\title{
Mobilizing nascent ties: A Qualitative Structural Analysis of social(izing) capital in newcomer networks
}

\author{
Sabine R. Bakker (D) \\ Institute for Management Research, Radboud University Nijmegen, the Netherlands \\ Email: s.bakker@fm.ru.nl \\ Special Issue Editors: Brea L. Perry, Bernice A. Pescosolido, Mario L. Small, and Ann McCranie
}

\begin{abstract}
This paper investigates the processes involved when newly hired employees need to simultaneously build up and mobilize personal network ties during their organizational socialization. It focuses on the quality of ties at an early formative stage, characterized by the lack of a tie history between actors. Social capital theory would suggest that such nascent ties do not offer optimal channels for the kind and volume of resources that newcomers (need to) rely on during socialization. To better understand how this apparent mismatch between tie quality and resource needs is handled from an ego-centered perspective, the paper analyzes personal network data from 24 newcomers in nine organizations, using an adapted form of Qualitative Structural Analysis. Three tie-level qualities are found to explain how the lack of tie history may be alleviated, circumvented, or compensated. They comprise (a) variants of openness experienced with stronger ties, (b) perceptions of a lowered threshold towards weaker ties, and (c) sources of legitimacy regarding latent ties. Based on these findings, the paper presents an integrated conceptual model to clarify how nascent ties offer channels for network resources during socialization and discusses the need for further research on the role of specific moderators for the investigated processes.
\end{abstract}

Keywords: personal networks; social capital; network resources; Qualitative Structural Analysis; tie mobilization; tie development; socialization; newcomers

\section{Introduction}

Analyzing personal networks from an ego-centered perspective offers researchers the opportunity to combine standardized methods of network data collection with qualitative inquiries regarding the processes underlying tie formation and mobilization as perceived by a focal actor. Such a combined approach is applied here to investigate the emerging personal networks of newly hired employees joining an organization, referred to as newcomers. At the focus of interest are the resources that these newcomers (need to) derive from ties during organizational socialization, ranging from support with their task performance over socio-emotional integration to career guidance (Iseke, 2007; Jokisaari \& Nurmi, 2012).

Organizational socialization refers to the early phases of initial onboarding and extended introduction to the job when newcomers still need to attain insider status (Cable, Gino, \& Staats, 2013; Ostroff \& Kozlowski, 1992). It comprises all more or less formalized organizational processes that support newcomers in their own efforts "to understand and master their new environment" (Morrison, 1993, p. 173). Their shared objective is to counter the insecurity that newcomers experience upon entering a context in which they are missing "comfortable routines or assumptions, having their senses inundated with unfamiliar cues, and searching to fit in socially" (Cable et al., 2013, p. 2). Resources provided by organizational insiders have been found to represent valuable 
social capital for newcomers towards these ends, helping to reduce anxiety (Harris, Li, Boswell, Zhang, \& Xie, 2014) and foster organizational commitment (Allen \& Shanock, 2013; Bozionelos, 2008), thereby increasing newcomer embeddedness and chances of their retention (Allen, 2006; Korte \& Lin, 2013). For research on organizational socialization, the social capital perspective has thus been found to offer a helpful theoretical lens (Fang, Duffy, \& Shaw, 2011; Morrison, 2002).

Befitting this specific context of interest, social capital is here defined as the aggregate of resources in the intra-organizational contact network of a focal actor (ego) to which s/he can gain access through the relationships (ties) to other organizational actors (alter) (Adler \& Kwon, 2002; Fang et al., 2011; Lin, 1999). As the term implies, these resources represent a metaphorical form of capital, complementing, catalyzing, or enhancing individual skills and competencies to satisfy needs and attain goals for ego as well as the organization (Nahapiet \& Ghoshal, 1998; Riemer, 2005). Indeed, developing social capital has been shown to foster the applicability and further development of newcomers' human capital in their new context and to predict successful integration (Bauer, Bodner, Erdogan, Truxillo, \& Tucker, 2007; Cable et al., 2013; Morrison, 2002; van der Werff \& Buckley, 2017). This invites a merger of socialization research with social capital theory (Batistič, 2014; Fang et al., 2011), implied in the description of intra-organizational network resources as "socializing" capital for newcomers, here.

Scholars dedicated to further integrate the two fields have called for theory development on how the quality (rather than the mere number or structure) of ties affects socialization (Korte \& Lin, 2013; Zhang, Fried, \& Griffeth, 2012). In answer to that call, this study investigates the quality of nascent ties-that is, the initial relationships forming between newcomers and insiders upon organizational entry. At the focus of this paper is the lack of a tie history between actors, asking how this particular quality characterizing nascent ties affects the development of newcomers' personal networks and intra-organizational social capital during socialization. This is to increase our understanding of the processes involved when newcomers need to simultaneously build up and mobilize resources from their emerging networks. Both researchers and organizations have an interest in better understanding what facilitates these processes, considering the various direct, indirect, and opportunity costs entailed where socialization is ineffective (for reviews cf. Bauer \& Erdogan, 2014; Fang et al., 2011).

To address this question, the paper proceeds as follows: Section 2 reviews central insights from research on organizational socialization and social capital to integrate them into a conceptual model and formulate a proposition to inform the following empirical investigation of newcomer networks. Section 3 introduces the research setting and describes the study's methods regarding data collection, processing, and analysis, explaining its adaptation of Qualitative Structural Analysis (QSA). In Section 4, central insights from the analysis are presented and Section 5 integrates them with regard to their implications for the paper's conceptual model and method, discussing its contributions and limitations.

\section{Theoretical background and proposition}

A growing body of research provides insights into newcomers' socialization from a social network perspective, focusing on their relational embeddedness rather than individual attributes or organizational measures (Allen \& Shanock, 2013; Fang et al., 2011; Holtom, Mitchell, \& Lee, 2006). The following review briefly summarizes central findings derived from this perspective, delineating how the socialization experience of newcomers is understood to differ depending on variabilities in their personal network configuration on the one hand, and the resources they can mobilize from network ties on the other hand (Bauer \& Erdogan, 2014; Jokisaari \& Nurmi, 2012; Korte \& Lin, 2013; Morrison, 2002).

\subsection{Mobilizing network resources}

For newcomers, the difference between their initial status as outsiders and becoming socialized as insiders lies in their ability to access intra-organizational resources "such as knowledge, advice, 
social credentials, and influence" (Jokisaari \& Nurmi, 2012, p. 82). While a part of these resources will be rather straightforward information, the most crucial among them go beyond what is easily codifiable in "manuals, training programs, organizational charts and job descriptions" (Jokisaari \& Nurmi, 2012, p. 78). Instead, it is primarily, if not only through interpersonal ties to insiders that newcomers can "acquire the attitudes, behaviors, and [tacit] knowledge they need to participate as organizational members” (Fang et al., 2011, p. 127).

Indeed, researchers have shown that access to such resources allows newcomers to effectively apply and further develop their knowledge and skills in their new foci of activity, helping them with learning and performance (Cable et al., 2013; Harris et al., 2014). Also, newcomers have been found to rely on their initial ties for reputational endorsements, allowing them an advance of legitimacy until they develop their own credibility and visibility within the organization (Iseke, 2007; Jokisaari \& Nurmi, 2012). And further, newcomers depend on insiders for developing a feeling of acceptance and belonging as well as an understanding of social norms and expectations at the organization (Bauer \& Erdogan, 2014; Morrison, 1993).

Their development of intra-organizational social capital is thus driven by the needs of attaining task mastery, role clarity, and social inclusion-all considered central measures of successful socialization (Batistič \& Tymon, 2017; Fang et al., 2015; Korte \& Lin, 2013; Morrison, 2002). To achieve either or all, newcomers cannot rely on their personal competencies or individual-level human capital alone, but will benefit from mobilizing resources through ties to insiders to catalyze or complement their own (Hansen, 1999; Iseke, 2007; Lane \& Sweeny, 2019).

\subsection{Developing network ties}

A newcomer's personal network thus represents the opportunity structure from which to derive intra-organizational social capital (Fang et al., 2011; Jokisaari \& Nurmi, 2012). Its size (both overall and relative to the size of the organization) as well as its composition delineate the resource repository on which the focal actor may potentially draw, since "actors in different network positions have differential access to resources and can provide different opportunities and resources to newcomers as they strive to integrate into the group" (Korte \& Lin, 2013, p. 412). Flap \& Völker (2001, p. 301) further demonstrated how "[d]ifferent network structures constitute different forms of social capital, depending on what goals the actor wants to attain" at the workplace. That is, a structure particularly apt to serve one need will make a personal network less apt to provide newcomers with social capital that is helpful in attaining other goals (Fang et al., 2011; Gargiulo \& Benassi, 2000; Riemer, 2005).

Overall, personal network ties are a necessary, yet insufficient condition for social capital development, because in the absence of "social ties, individuals do not have access to social resources” (Spillane, Kim, \& Frank, 2012, p. 1112). Accessibility represents merely one aspect, though, whereas a given ego's social capital further depends on processes of searching, selecting, activating, and mobilizing ties (Small \& Sukhu, 2016), and actors will differ in the resources they draw from their networks, even if their networks do not differ in the potential of resources they provide (Gulati, Lavie, \& Madhavan, 2011).

Conversely, resource exchanges can also lead to the development of network ties in the first place, which represents a valuable step towards newcomer socialization in itself: When new ties to insiders emerge (expanding network width) or extant ties grow stronger or develop multiplexity (adding network depth), newcomers become increasingly embedded at the organization (Allen, 2006; Holtom et al., 2006). As such, they are better insulated against negative experiences and buffered against shocks, with stronger pull-forces tying newcomers in and increasing the perceived costs of leaving the organization (Mitchell, Holtom, Lee, Sablynski, \& Erez, 2001).

\subsection{Integration in a conceptual model}

It is important for research investigating organizational phenomena from a social capital perspective to acknowledge that the connections between the aspects involved are "more complex 
than the one-way, direct, static relationship implied" in linear models of causation (Perry-Smith \& Shalley, 2015, p. 90). Causality concerns arise where either is suggested to be solely the cause or effect of the other, especially in a cross-sectional design (Fang et al., 2011; Korte \& Lin, 2013; Morrison, 2002). Respectively, Perry-Smith \& Shalley (2015, p. 92) have recommended a "model that describes a more fluid situation," where there are reciprocal effects between variables that can be both enhancing or constraining.

The conceptual model underlying this study adopts such a perspective on personal networks, social capital, and newcomer socialization as "a case of reciprocal causation" (Perry-Smith \& Shalley, 2015, p. 100). The mobilization of personal network ties is argued to increase a newcomer's social capital through the provision of resources; exchanges of social capital resources are taken to foster the development of network ties. Both, an increase in mobilized social capital and the development of personal networks at the organization will positively affect newcomer socialization. Neither of these poles represents a sole possible starting or end point. Through their integration, the model points out the effects of each of these processes and how their combination can create a self-reinforcing loop.

Moreover, this integrated perspective serves to draw attention to the contingencies of the model that remain a black box, offering the basis for researchers to investigate "the factors that can start, stop, or modify" the mutual effects between its elements (Perry-Smith \& Shalley, 2015, p. 100). The focus of this paper lies on one of these factors in particular: Newly emerging ties will, by definition, be characterized by a lack of tie history between actors. Focusing on this aspect here is not to deny that there is a range of other contextual factors (Fang et al., 2011; Jokisaari \& Nurmi, 2012). Also, it is explicitly not taken to prevent newcomer socialization. Rather, it is considered a particular quality of interest to better understand nascent ties as channels for network resources and a starting point for personal network development.

\subsection{Lack of a tie history}

As newcomers start out at an organization, most if not all of their ties to insiders will lack a prior history, meaning that they cannot draw on a track record of previous interactions. The latter is considered a central premise for ties to be called upon for social capital, though (Riemer, 2005; van der Werff \& Buckley, 2017). Researchers would consequently expect that newcomers face impediments when it comes to resource mobilization, based on three lines of argumentation to be reviewed in the following: First, nascent ties without a history will still lack the basis for developing tie strength, trust, and mutual commitment; second, newcomers would need these ties to channel resources before they can meet the entailed norms of reciprocity; and third, "essential lubricants" (Devadason, 2011, p. 639) for tie formation and resource mobilization will not work in their favor.

Regarding the first line of argument, social capital theory contends that it takes time to develop ties that are robust and committed enough to provide support, especially when it comes to more tacit and complex resources (Bauer \& Erdogan, 2014; Lee, 2009). The propensity to offer broadband channels for such resources is considered the particular "strength" of strong ties-that is, those that have developed over a longer duration with more frequent and/or intense interactions (Ash, Saks, \& Lee, 1998; Burt, 2001; Granovetter, 1983; Slaughter \& Zickar, 2006). Within organizations, those are also the ties that have been found to "facilitate the flow of important resources, as people can place more demands on those closest to them" (Lane \& Sweeny, 2019, p. 81) and actors providing resources "feel more comfortable sharing information that requires trust and candor across stronger relationships" (Perry-Smith \& Shalley, 2015, p. 94).

In other words, "it takes time for newcomers to pass the "inclusionary boundary"' (Jokisaari \& Nurmi, 2012, p. 90) and until then, "there is no reason to assume that others are necessarily motivated to help" (Higgins \& Kram, 2001, p. 279), even in an organizational setting. While this is intuitive enough, it does not mean that a lack of tie history will automatically be overcome as time passes. Rather than relying on the mere number of weeks or months of tenure, building 
a tie history will depend on the investments newcomers make "for strengthening relationships with various insiders or to establish trust and ease" (Fang et al., 2011, p. 136). Yet we know from research on tie formation in new foci of activity that newcomers "must not only negotiate relations with a new set of acquaintances, but also master new skills, take on new responsibilities, and fulfill new obligations" (Small, Deeds Pamphile, \& McMahan, 2015, p. 93). Their capacity to invest in tie strength is at least limited while they are also "busy learning their new duties" and still rather "concerned about negative relational consequences (e.g., social rejection) associated with insider interactions" (Fang et al., 2011, pp. 138-139).

Extant research has attested that socialization entails a steep learning curve especially at the beginning (Allen \& Shanock, 2013; Ostroff \& Kozlowski, 1992) and that newcomer anxiety is highest upon organizational entry (Batistič, 2014; Bauer et al., 2007). Ties in their early formative stages, by implication, would not seem to offer optimal preconditions for channeling the kinds and volume of resources that newcomers require at the beginning of socialization, unless they are characterized by qualities compensating for the initial lack of tie strength.

Meanwhile, strong ties are not the only possible source of social capital and weaker ties can provide valuable resources for newcomers, as well. Insiders may well feel personally motivated to support them or obliged to do so by organizational roles and policies (Korte \& Lin, 2013; Mollenhorst, Volker, \& Flap, 2014). Still, for any and all organizational actors, relationships and social capital are something that they "cannot just 'build and use' [...] for individual or organizational benefit without adequate investment in reciprocity" (Maak, 2007, p. 334).

This brings us to the second line of argument casting doubt on the propensity of nascent ties as channels for social(izing) capital: They are bound to be characterized by an asymmetry in resource exchanges, as newcomers are not in a position yet to fully meet norms of reciprocity during socialization. That is, newcomers are initially limited to their human capital when it comes to reciprocating for the support they receive, as they still lack company-specific knowledge, control over internal resources, power, or influence as well as professional experience upon organizational entry (Iseke, 2007).

Network resource exchanges do not need to be symmetrical, per se. Differences between the nature or amount of resources that actors bring into a network can, in fact, be a driving force behind their exchange (Burt, 1997). Also, reciprocation leaves unspecified when incurred obligations are to be repaid, whether it will be in the same "currency" or even involving the same dyad of actors (Portes, 1998). The normative state of reciprocity further stresses that the options to enforce reciprocation or sanction defectors remain limited (Randel \& Ranft, 2007; Ripperger, 2003). However, if actors are perceived as free-riders, profiting from intra-organizational social capital without making appropriate contributions in turn (Adler \& Kwon, 2002; Riemer, 2005), they will not be considered attractive or trustworthy enough for continued interaction where there is room for discretion (Bourdieu, 1983; Nahapiet \& Ghoshal, 1998).

Thus, overly one-sided interactions between newcomers and insiders are less likely to be repeated and their nascent ties less likely to be sustained (Hatala, 2006), unless they are characterized by qualities that reduce the pressure on newcomers when it comes to mobilizing support that they cannot reciprocate for as yet.

Regarding the third line of argument, extant research on tie formation also indicates that newcomers are at a disadvantage when it comes to decisive mechanisms of personal network and social capital development (Dahlander \& McFarland, 2013). Homophily is one of those central drivers, "since tie formation occurs in an uncertain and broad context of strangers applying short-term strategies to quickly assess and forge ties on the basis of shared traits" (Dahlander \& McFarland, 2013, p. 71). For newcomers, this means that tie formation will come most easily to other newcomers. Exactly because of the homophily among them, however, peer ties are far less likely to offer resources that can complement or expand their own.

Further, tie formation is known to be attracted by status and centrality, so that "a wellconnected individual is more likely to collaborate with other well-connected individuals than to reach out to someone who is more peripheral" (Dahlander \& McFarland, 2013, p. 91). Actors 
who have more or more attractive resources at their disposal will be preferred partners for exchange relations (Riemer, 2005). Newcomers, meanwhile, will typically start out on their efforts to attain insider status from the fringes of the organizational network (Higgins \& Kram, 2001) and have, respectively, been compared to minorities and counted under groups of marginal actors in organizations (Ibarra, 1993; Iseke, 2007).

Finally, tie formation is driven by propinquity, where actors become aware of each other through exposure and convenience (Dahlander \& McFarland, 2013; Spillane et al., 2012). Lane \& Sweeny (2019) found that for newcomers, this means that initial ties align closely with an organization's formal structure, whereas insiders exert more agency in forming ties where they "identify desirable and matching traits in potential partners" (Dahlander \& McFarland, 2013, p. 69). Also, the "surplus" value of social capital arguably begins where it goes beyond the organization's functional "blueprint" (Flap \& Völker, 2001, p. 316).

In summary, due to the lack of a tie history between newcomers and insiders, nascent ties are argued to be characterized by a mismatch between attained tie strength and resource needs as well as a heightened asymmetry regarding reciprocity and status. This paper proposes to investigate which other or additional qualities enable the mobilization of resources through nascent ties in light of these aspects, to increase our theoretical understanding of how newcomers develop intraorganizational social capital.

Proposition. Nascent ties to insiders that newcomers can mobilize for social capital are characterized by qualities that compensate for, alleviate, or circumvent their lack of a tie history.

\section{Data and method}

Investigating newcomer networks with regard to the formulated proposition requires both measures on the qualities of newcomers' network ties and mobilized social capital as well as access to their "individual perceptions, subjective meanings, [and] frameworks of reference" (Wald, 2014, p. 76) to reconstruct their experiences regarding tie development and resource mobilization at an early stage of socialization. This warrants a research design incorporating a mix of qualitative and structured data.

\subsection{Field access}

The study at hand, respectively, draws on a comprehensive data set collected from 24 newcomers in nine different organizations about 3 months after starting out on their jobs as part of a three-waves panel study in Germany. All of them were recent high school graduates, between 17 and 20 years of age (with a median just under 19 years), entering their first professional employments. The newcomers' recruitment for participation in the study was facilitated because their training as newcomers at the employing organizations included a higher education program in International Business studies. For this program, 28 newcomers were joined in a cohort cutting across their respective employers to follow academic lectures together, through which they were approached for the panel study by the author. Admission to the program required the highest secondary degree to be attained in Germany ("Abitur") or equivalents, with above-average grades. It aims to train newcomers in various areas of international business, preparing them for roles in administration and management. All newcomers in the cohort had signed employment contracts for a minimum duration of 3 years. In addition, the organizations' investment in their academic training signaled the intent of a longer term commitment.

In line with the study's informed consent agreement, data collected from two of the 28 newcomers had to be excluded from the analysis since they dropped out of the program at a later stage, effectively withdrawing from the panel (representing $7 \%$ attrition). Data collected from two other newcomers were not included in the analysis here, due to diminished comparability with the rest of the sample (that is, one newcomer worked as self-employed entrepreneur; another had 
switched employers and was still waiting to be onboarded at the second organization at the time of the first wave of data collection). As for the remaining group of 24, female newcomers represented a slight majority (62\%), as they often do in higher education degrees for the humanities and social sciences in Germany (Francesconi \& Parey, 2018). While the given type of field access entails the limitations of a convenience sample, it matches the objective of the study, which is the depth of understanding for variations in newcomer experiences, rather than randomization or the generalization of results.

The sample includes a range of organizational sizes and industries, comprising a small-tomedium-size enterprise (SME), three large enterprises (LE), a public-private partnership (PPP), and four multi-national enterprises (MNE). It includes operations in IT solutions and consulting, producers of medical- and heavy equipment as well as financial services, engineering, and pharmaceuticals. All organizations engaged in deliberate onboarding and socialization practices, albeit in different forms and to varying degrees of institutionalization.

\subsection{Data collection}

At the first wave of data collection, the newcomers were asked about their socialization experiences in semi-structured interviews with the author after 3 months on the job. The interviews were framed by open, qualitative parts at the beginning and at the end, probing for their onboarding and initial working experiences upon entering the organizations. Questions were asked to follow up on insiders, ties, and resources mentioned and invited "respondents to add as much individual information as they considered relevant" (Wald, 2014, p. 77). This resulted in rich texts providing contextual information on newcomer-insider relationships and the companies' socialization measures.

Nested within the bracket of the open beginning and ending, there was a standardized part to collect structured data on the newcomers' personal networks. This part was designed in a three-step approach to systematically gather information on which kinds of network ties to which organizational insiders the newcomers had mobilized for which kinds of social capital up onto the time of the interview.

In the first step, the newcomers were asked to list the names of their contacts at the organization, guided by a combination of name generator questions. Examples include "With whom did you collaborate directly for the tasks or projects you worked on?", "With whom do you prefer to spend your lunch breaks?", or "Are there any recent contacts which you find interesting?". The list of name generator questions was designed and pretested to help newcomers with the recall of a wide range of ties, rather than just their immediate proximity or merely one specific function of ties (such as communication, advice, or friendship networks).

As a second step, the newcomers were asked to characterize both the alters listed and their relationships with them with the help of name interpreter questions. These included alters' gender, their roles at the organization, and the perceived age difference between ego and alter. Ties were further specified regarding the frequency of contact and how intense ego perceived the contact to be on a professional as well as on a personal level.

In the third step, newcomers were asked to indicate the different types of resources derived from each listed alter. They reported concrete experiences of support (Small \& Sukhu, 2016) regarding 19 statements adapted from Iseke's (2007) typology of social capital for marginal actors in organizations. Probes related to learning and task-performance (for example, "This person explained to me why things are done a certain way at the organization"), career-related guidance and promotion (for example, "This person has provided me with opportunities to become visible with performance within or beyond my team"), and socio-emotional integration (for example, "This person has made me feel accepted and appreciated").

The length of interviews averaged at 1:05 hrs (ranging from 43 mins to 1:40 hrs). Newcomers were not asked to also report alter-alter ties, which reduced respondent burden and the risk of panel attrition, but does represent a limitation of this study. 
Phase 1: Structural descriptions of network data summarized in analytical questions.

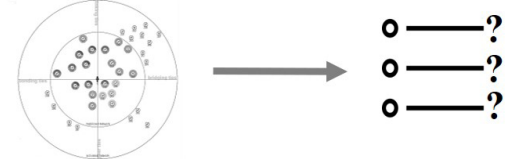

Phase 2: Analytical questions guide close readings of narrative data.

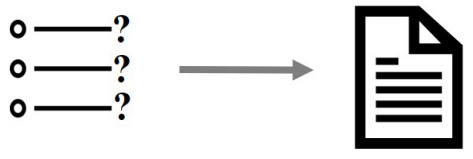

Phase 3: Iterations between structured and narrative data to refine initial readings to within-case analyses.

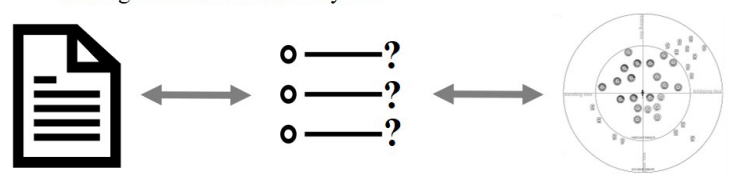

Phase 4: Across-case analysis probing for similarities and differences to develop answers regarding the research question/proposition.

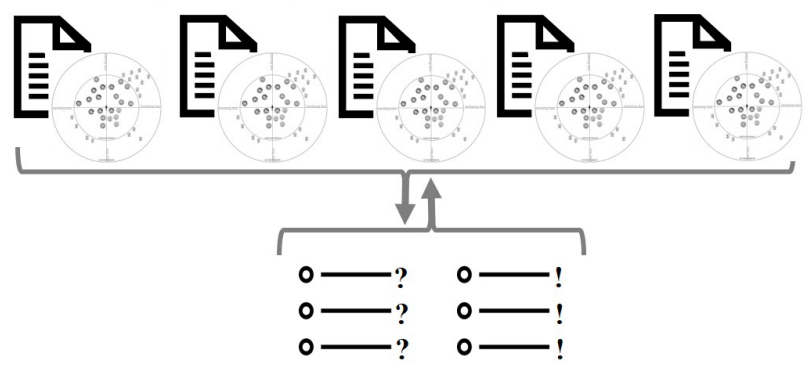

Figure 1. Phases of the conducted Qualitative Structural Analysis.

\subsection{Data analysis}

To triangulate the structured and narrative data collected, an adapted approach of Qualitative Structural Analysis was conducted (Herz, Peters, \& Truschkat, 2015), facilitated by the QDA software Atlas.ti. As the name implies, the data analysis procedure of QSA offers a "combination of the analytical perspective of structural analysis and analytical standards taken from qualitative social research" (Herz et al., 2015, p. 1). Figure 1 summarizes the phases of the procedure as carried out for the study at hand that are to be explicated in the following.

Phase 1: As an initial step of theory-guided processing, the standardized network data were visualized in graph frameworks using VennMaker (Schönhuth, Kronenwett, Gamper, \& Stark, 2014). Each newcomer's network configuration was first explored in a case-by-case analysis, to develop alter, tie, and resource-focused descriptions based on sensitizing concepts from social network analysis (Herz et al., 2015). These structural descriptions were documented in codable form through memos as a means to stimulate initial readings of data interpretation (Herz et al., 2015). They were summarized in analytical questions, inquiring "why this structure is as it is, and what kinds of significance this holds for ego" (Herz et al., 2015, p. 5), such as

Ego barely mobilized resources from ties to alters outside of his immediate proximity. Are there indications for why bridging ties could or would not provide social capital? 
Table 1. Data structure of findings from the Qualitative Structural Analysis.

\begin{tabular}{|c|c|c|}
\hline $\begin{array}{l}\text { First-order concepts } \\
\text { Informant-centric terms and codes }\end{array}$ & $\begin{array}{l}\text { Second-order themes } \\
\text { Theoretical categories }\end{array}$ & $\begin{array}{l}\text { Aggregate dimensions } \\
\text { Analytical categories }\end{array}$ \\
\hline $\begin{array}{l}\text { (metaphorical) shared space; locus set outside of daily routines; away } \\
\text { from the office, e.g. "on the fair"; more leveled playing field; insiders } \\
\text { are more accessible "when you are on the road together"; }\end{array}$ & Common ground & \\
\hline $\begin{array}{l}\text { identifying with an in-group; not one of 'the others'; isolated teams; } \\
\text { detached departments; self-ascribed separation; externally imposed } \\
\text { separation; being "automatically written off'; definition by opposition; }\end{array}$ & Inclusion by exclusion & $\begin{array}{l}\text { Extending an advance in trust, } \\
\text { assuming a good fit } \\
\text { before it is proven and }\end{array}$ \\
\hline $\begin{array}{l}\text { colluding; conspiring with alters; witnessing unofficial practices of } \\
\text { "how things really get done"; being in cahoots; bending or breaking } \\
\text { the rules; sharing confidential information about "what goes on"; } \\
\text { being privy to gossip; being sent "undercover"; insider by default; }\end{array}$ & Partners in crime & accepting vulnerability. \\
\hline $\begin{array}{l}\text { continuity beyond individual dyads; "I'm not the first newcomer they } \\
\text { dealt with"; many came before, many will come after; "They're } \\
\text { familiar with the principle of new guys"; being new is somewhat of a } \\
\text { "collective feeling"; }\end{array}$ & Chain effect & LOWERED THRESHOLD - \\
\hline $\begin{array}{l}\text { interpersonal click; "matching wavelengths"; unspecific fit of } \\
\text { personalities; matching ways of working; feeling "in tune" or "in } \\
\text { sync" with insiders; "just a good match"; different from homophily; }\end{array}$ & Matching wavelengths & $\begin{array}{l}\text { (actual or anticipated) } \\
\text { transaction costs and } \\
\text { social risks of tic mobilization, }\end{array}$ \\
\hline $\begin{array}{l}\text { cognitive map; knowing who is who; who does what; who is } \\
\text { important; whom (not) to approach how; how crucial it is "to get this } \\
\text { right" at the organization; which ties can offer 'shortcuts'; }\end{array}$ & Know-who & perceived stress or pressure. \\
\hline $\begin{array}{l}\text { generalized support culture; resources considered a shared value } \\
\text { repository; "some kind of trove for you to draw from"; collective } \\
\text { goods; equal claim; "really everyone profits from it"; }\end{array}$ & Collective goods & LEGITIMIZATION - \\
\hline $\begin{array}{l}\text { learning-tasks; assignments require alters' resources; foster higher } \\
\text { frequency of interaction; "I got to talk to them all constantly"; }\end{array}$ & $\begin{array}{c}\text { Task-inherent } \\
\text { resource mobilization }\end{array}$ & $\begin{array}{l}\text { convince themselves (and } \\
\text { insiders) that their claim to }\end{array}$ \\
\hline $\begin{array}{l}\text { project ownership with network component; having "to bother people } \\
\text { a lot"; shared objectives to be achieved. }\end{array}$ & $\begin{array}{l}\text { Project-inherent } \\
\text { networking }\end{array}$ & good as anyone's. \\
\hline
\end{tabular}

Phase 2: These analytical questions derived from the structural descriptions of each newcomer's network data served to sensitize the initial close reading and coding of their corresponding interview transcripts (Herz et al., 2015). The resulting list of informant-centric codes was then thoroughly revised and applied in the second round of close readings, aiming to increase the consistency of coding between interviews.

Phase 3: Through further iterations, the analytical questions derived from the structured data (phase 1) were addressed or answered based on the newcomers' reports in the interviews. Vice versa, additional or different questions spurred while coding the interview transcripts were taken to the structured network data in turn (Herz et al., 2015). As such, the QSA procedure allowed for the iterative development of second-order, theoretical categories where first-order codes cooccurred in clusters or re-occurred in variations (Gioia, Corley, \& Hamilton, 2013).

Phase 4: By repeatedly drawing on both, the visualized network data and contextualizing interview narratives, the initial readings were further developed and extended to an across-case analysis. Cases were compared in terms of how they were similar or different regarding the mobilization of resources in the absence of a tie history. Based on this across-case analysis, the second-order themes were further revised and aggregated into broader conceptual dimensions.

\section{Findings}

Table 1 provides an overview of the resulting data structure (Gioia et al., 2013), summarizing the findings emerging from the QSA. It shows the aggregate dimensions identified (right column) 
and which second-order themes they comprise (middle column). They further show how these were developed from the data, providing illustrative examples for their grounding in informantcentric codes as first-order concepts (left column). Quotations are referenced with the indices of transcripts and coded passages from Atlas.ti in the following.

Social capital theory would suggest that a lack of tie history can delay or limit the mobilization of ties in their initial stages of development. This paper, therefore, proposes that nascent ties between newcomers and insiders may be characterized by qualities that compensate for, alleviate, or circumvent an initial lack of tie history to facilitate resource mobilization. Clearly, the newcomers under study did perceive their lack of a tie history with insiders as a challenge upon organizational entry, when "it was like, at the beginning, you really don't know any of the others" (97:90). Their reports echo the notion that the value of social capital tends to be felt the most keenly where it is missing (Riemer, 2005). Still, they were able to mobilize their nascent ties to insiders within the first 3 months upon joining their organizations, for a wide range and often also for a considerable volume of social capital resources.

\subsection{Openness in the absence of a tie history}

The first tie-level quality that facilitated this mobilization emerging from the data was openness. It refers to a characteristic of newcomer-insider ties that allowed them to be called upon for support by relying on a mere advance of trust. Despite the lack of a tie history, newcomers did not perceive insiders to be guarded or hesitant towards them in these cases. "Being open" was, in fact, a strikingly prominent phrase in the newcomers' narratives regarding positive experiences with mobilizing resources. It would relate either to insiders being open towards newcomers, newcomers considering their own openness helpful during socialization, or an organizational culture signaling openness. One explanation for the concepts' prominence was that newcomers were not taking this for granted at the early stage of their organizational membership: "I mean, when you are new to the department, you don't barge into the house by kicking in the door. But somehow, a lot of it was just coming from [their] side" (78:95).

Based on the newcomers' reports, openness was found to come easier where they and insiders got to bond on some metaphorical form of "common ground," where strong in-group cohesion was created by exclusion of others, and where it resulted from some form of colluding. First, the metaphor of a common ground subsumes experiences in which newcomers met or intensively bonded with insiders that shared a particular framing. They all stressed the locus bringing them together in terms of a co-occupied shared space (for instance, where they were "on a project together," "on assignment," or "on a business trip"). Strikingly, these loci were all set away from the office and outside daily routines. This was described to offer newcomers a (more) leveled playing field to engage with insiders, who were perceived to be more accessible for them on such common ground. As one newcomer put it:

Well it's like, when you are on a fair like that with them, then it gets really - you get to see a lot more of what they do then, but otherwise it is more that they are working by themselves, and also not necessarily together. (87:153)

Newcomers further experienced openness from in-groups in which they felt included because others were excluded from them. Some were socialized in a team or department that was somewhat separated from core value creation processes and required or allowed for little collaboration with insiders from other parts of the organization. The reasons for such separation could be either selfascribed or externally imposed. One newcomer reported that the moment she joined her assigned team, other departments had a preformed negative opinion of her, as "just like that, you are automatically written off” (84:77). Another described growing into a team that actively set itself apart by distinct working hours and an earlier lunch break (87:25). These reports indicated that egos 
felt included and could access resources from ties of their in-groups, because despite being newcomers, they shared the focal collectivity's internally oriented openness resulting from externally oriented closure towards its "true" outsiders.

In a more extreme form of this inclusion by exclusion, openness was perceived to stem from newcomers at times finding themselves in cahoots with insiders on practices that involved bending or even breaking official rules within the organization. One team, for instance, sent their newcomer to a trade fair to conduct a competitor analysis, because he would not be recognized as an employee: "That meant that I basically walked around undercover, having conversations and so on with the competition" (96:20). In this variant, newcomers felt integrated because they witnessed or were actively taught how things really got done, as opposed to how they were supposed to be done by standards of regulations, compliance, or even the law. When alters shared insider information, gossip, secrets, and unofficial or incriminating processes with newcomers (or at least did not intentionally exclude them when sharing those amongst each other), this was perceived as strong indications of openness. In the words of one newcomer, it was "just the kind of stuff they can tell you about what goes on at [company name] that you wouldn't come across or read about, not even internally" (78:117). Because non-members of the in-group, even within the same organization, are not (to be) privy to these practices or information, accessing them assigned newcomers an insider status quasi by default.

Overall, newcomers were sensitive to signals of openness and picked up on them gratefully. They were perceived to indicate an advance of trust granted, as insiders sharing authentic behavior implicitly accepted the risk of vulnerability. Where ties made newcomers feel more at eye-level with insiders, distinguished from true outsiders, in-the-know or even "partners in crime," they were perceived as valuable sources of social capital.

\subsection{A lowered threshold to tie mobilization}

Not all nascent ties could profit from the lubricant effects leading to openness in the absence of a tie history described above. For those that did not, newcomers reported perceiving substantial hurdles when it came to actively approaching insiders for access to resources. The causes varied widely, from personal attributes, such as being timid, to an organizational culture branding knowledge-sharing as a burden, for instance. Anything reducing the perceived threshold on or beyond the dyad-level facilitated resource mobilization for newcomers, if not by encouraging them to build social capital then simply by making it less unlikely. Three such mechanisms were evident in the data.

First, newcomers reported that when socialization was highly institutionalized in their organizations, they perceived less pressure on themselves as individuals, as many peers had proceeded them and many would follow after. Understanding that their trajectory was a common and recurring experience at the organization allowed newcomers to relativize the newness of their personal experience and they felt less stress or insecurity about approaching insiders who were accustomed to dealing with newcomers:

I really notice that now already, well, that it's really good that you are sitting in the same boat with them, that you are not on your own, but there is really some sort of a collective feeling to it. $(93: 138)$

A second recurring theme in the newcomers' reports was that they simply had "a click" with certain insiders. Rather strikingly, several newcomers referred to this dyad-level fit as "being on the same wavelength" $(85: 85 ; 93: 67 ; 96: 68)$. The metaphor implies that ties were characterized by harmony or the absence of dissonance. Interestingly, newcomers seemed unable to pinpoint its sources more precisely, other than "somehow it was just a good match" (85:81), even despite considerable age gaps and/or differing genders. Also, these ties could remain rather formal and distanced and still provide valuable social capital (e.g., 85:81). As such, a matching of wavelengths 
differs from those forms of homophily that rely on clearly perceptible attributes (Appleyard, \& Cross, 2016).

A third, prominent mechanism involved newcomers profiting from their emerging "knowwho" at the organization. The range and complexity of their descriptions comprised not only developing an understanding of who is who (79:77) and who does what at the organization (80:79), but also who is important (94:111), whom (not) to approach how (89:177), when and how to go around whom (84:62), and how important it is in their particular organization to "get this right" (87:125). Knowing whom to best approach for what was considered a crucial factor for mobilizing ties in the absence of a tie history, particularly in large-scale organizations, since "it's just so much easier to approach someone when you know them at least by name, like knowing where they sit, what their job is" (85:145). It further helped newcomers to identify particular ties as short-cuts to resources and lowered their perceived transaction costs: "Because it has, on the one side, saved me so much time, and on the other side also, just, general effort, really" (89:142).

Several newcomers pointed out that they had been actively encouraged by their supervisors when it came to developing know-who. One of them recalls instances "when I asked, "Who is that?' and then my supervisors would pull out the organizational chart and show me, 'This guy, here.', like with a photo" (83:55); another reported how "we really put an emphasis on this, so that I would just know these people and what they do and whom I need to turn to when I have questions and [name of mentor] was actually quite pushy about that" (85:160). As such, know-who emerged as a distinct and desirable skillset from the newcomers' narratives, not just a side effect but rather an end of socialization in its own right.

\subsection{Sources of legitimacy for mobilizing resources from ties}

Even where there was no particular form of openness boosting tie mobilization and the perceived threshold to approach insiders remained high, newcomers reported various experiences in which legitimized requests made it easier for them to derive resources from nascent and even utterly latent ties. Where there was a perception of legitimacy, newcomers felt less daunted by inquiring information, input, or time from insiders. Variants included an organizational culture in which resources are considered collective goods, assignments that necessitate collaboration from insiders, and projects with an inherent networking element.

Regarding the first, mobilizing social capital was often legitimized for newcomers by a culture of generalized support at the organization, in which resources are considered a common wealth or "some kind of trove for you to draw from" (86:128). While situated at the organizational level, such an understanding of intra-organizational social capital as a shared value repository also affected the quality of newcomer-insider ties. Newcomers noticed it having an equalizing effect, making their claim as good as anyone else's: "Actually everyone can draw on this, no matter if in marketing or in production or the receptionist downstairs at the gate or whoever, because, well, really everyone profits from it, I think" (83:138).

In the other two variants, newcomers were either empowered to request resources from insiders through individual tasks they were given or they took ownership of a project that intrinsically required them to mobilize ties. Access to resources mostly increased along with the frequency and intensity of interaction with insiders as a result of newcomers completing their assignments, some seeming almost deliberately designed with socialization objectives in mind:

Since I had to collect everybody's experiences on this somehow, like, like - for example, what you need to somehow survive in this department; Or which emergency contact numbers they have saved; Or which SOS-emails - and so I, I got to talk to them all constantly. (92:97)

For several newcomers who were assigned their own projects to take on, approaching alters to request support was a central aspect to them. Their need to work on these projects gave newcomers 
a feeling of legitimization to mobilize resources, even where the motivation of insiders to provide them was low, as in this newcomer's illustrative narrative:

So I had to do some serious networking [laughing]. Yes, because, well the files themselves that I was dealing with were - really - terribly boring, but I talked to many, many, many people, who, they all didn't want me to talk to them about this stuff, because it was so unimportant [for them], what I wanted to get from them [laughing]. So I had to bother people a lot. I got much better at that now than I used to be. $(85: 186)$

This latter variant of legitimacy related especially, albeit not exclusively, to the mobilization of weak and very latent ties. Here, the QSA approach was instrumental in identifying it as an explanation for insiders providing newcomers with social capital although they seemed unlikely sources based on their tie characteristics.

\section{Discussion and conclusion}

The proposition investigated through this study surmised that nascent ties between newcomers and insiders were characterized by qualities that alleviate, circumvent, or compensate for an initial lack of tie history to facilitate resource mobilization. The data analysis provided evidence that the lack of tie history indeed represents a challenge and contributes to "newcomer anxiety" (Cable et al., 2013) during socialization. Based on the findings discussed above, resource mobilization now represents less of a black box than it did in the conceptual model described at the outset of this paper: Nascent ties between newcomers and insiders could be mobilized for social capital resources where they were characterized by openness, compensating for a basis of trust that still needed to develop; by a lowered perceived threshold, alleviating newcomers' weariness about approaching insiders for resources; and by legitimacy imbued on newcomers' requests to circumvent their initially weak intra-organizational standing.

Through the informant-centered, qualitative approach of the analysis, it was possible to get a better understanding of the variance in newcomer experiences as well as the recurrent themes in their reports. Bonding with insiders on (more) common ground and finding inclusion through exclusion or by being "in cahoots" with each other emerged as themes, illustrating how openness can foster resource mobilization for newcomers. Institutionalized socialization was perceived to create a sort of chain effect, lessening the pressure on individual dyads, so that the lack of tie history on the interpersonal level imposed less stress on newcomers. When newcomers and insiders found themselves on matching wavelengths, this made resource mobilization low on effort and friction losses. And where newcomers could draw on know-who, they saved on (actual or anticipated) search and transaction costs. Despite the lack of a tie history with insiders, newcomers were empowered to mobilize resources from nascent ties and even their most latent contacts when they felt they had a legitimate claim. Sources of such legitimacy were found in an organizational culture that treats resources as collective goods and in tasks or projects designed to make it a newcomer's job to approach insiders and draw on their resources or experience.

Based on these findings, the refined conceptual model as depicted in Figure 2 now offers a more complete picture of how newcomers initiate their personal network development and the mobilization of social capital during socialization, despite the absence of a tie history with insiders: Intra-organizational ties may develop and then provide social capital resources or result from resource exchanges. For newcomers, the mobilization of social capital resources from their emerging personal network is facilitated when stronger ties are characterized by openness, there's a lowered perceived threshold regarding weaker nascent ties, and/or sources of legitimacy help them with approaching even latent contacts at the organization. 
Figure 2. Refined conceptual model.

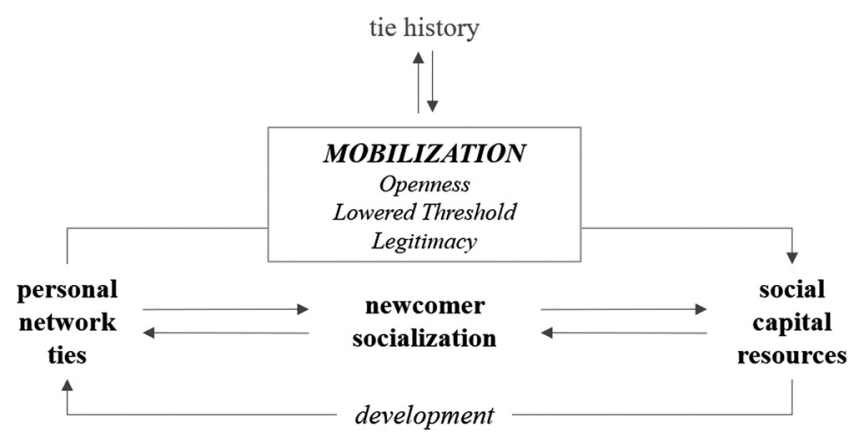

In terms of the paper's contribution towards theory development and organizational socialization practices, some insights expand on specific aspects identified by prior research on tie formation in new organizational foci. With regard to the role of propinquity in spurring tie formation (Lane \& Sweeny, 2019; Spillane et al., 2012), it is worth noting that newcomers were found to also profit profoundly where they find proximity with insiders on a metaphorical common ground. For this, the findings indicate that it is advisable to bring newcomers and insiders together off-site and outside daily routines. Onboarding measures often enlist this approach; yet, due to time or resource constrictions, they mostly do so for teambuilding amongst newcomer cohorts (while peers, ironically, also bonded easily at the office). One clear recommendation derived here for organizational socialization is thus to encourage insiders to let newcomers tag along whenever they are "out and about" on the job, anyway.

Besides bringing newcomers and insiders closer on a physical or metaphorical common ground, organizations can foster newcomers' know-who as a form of cognitive proximity. Socialization research has long acknowledged the importance of newcomers developing cognitive maps of who does what at their organization (Batistič, 2014; Borgatti \& Foster, 2003). The analysis of newcomer narratives studied here added insights into the complexity and additional layers of information that these cognitive maps grow to carry, even at an early stage after organizational entry. Crucially, the findings pointed out that know-who (as opposed to social capital) can be both, passed on among newcomers and rather directly transferred to them from insiders. Considering its catalyst effect on resource mobilization, this recommends deliberate investments in fostering know-who both for newcomers and organizations.

When it comes to what we know about the role of homophily, the findings here confirm that it offers "an efficient search strategy and means of reducing uncertainty" (Dahlander \& McFarland, 2013 , p. 74) in the context of tie formation among strangers. An interesting variant encountered that invites further research is the matching of wavelengths between newcomers and insiders. It was perceived to foster resource mobilization through a "reduction in communication apprehension afforded by interpersonal similarities" (Spillane et al., 2012, p. 1115), although they could not be based on observable commonalities (Levin et al., 2016) and diverged from extant theory regarding the role of gender differences or a perceived age gap.

Finally, recommendations can be derived for organizations with regard to the effect of status attraction in tie formation. To counter the renowned Matthew effect, driving tie formation based on how well connected actors already are (Dahlander \& McFarland, 2013; Riemer, 2005), socialization measures can quite literally make it a newcomer's job to approach insiders and their job to provide newcomers with resources through a deliberate design or choice of tasks and projects. Also, the study showed that fostering a culture in which resources are treated as collective goods has a perceptible equalizing impact for newcomers, down to the tie level.

From a critical research perspective, it is crucial to note the bonding effect that newcomers reported to experience when they became privy to irregular or even illegal practices in the teams or departments they joined. For organizations committed to compliance, it should raise concerns 
that colluding with insiders to bend or break the rules can offer a valued source of integration for new employees as they strive to feel accepted as insiders. This has implications for efforts to foster a culture of ethics, internal CSR policies, and measures taken to encourage and protect whistleblowers, right from the start of organizational membership.

Even within the given sample, the elaborated aspects are not exhaustive. Due to the focus on tie-level qualities, findings regarding primarily individual-level attributes or organizational-level tactics were not addressed, although both have strong moderating influences as well (Fang et al., 2011; Jokisaari \& Nurmi, 2012). While this study had a second focus of interest, regarding how the lack of reciprocity characterizing nascent ties affects network development, the respective results could not also be addressed within the scope of the paper at hand.

The sample itself offered advantages regarding both variability and comparability, but it is limited with regard to representativeness. All newcomers studied here were young professionals entering their first employments, as such representing merely one particular subgroup of newcomers socialized in organizations. Also, the organizations studied here actively recruited newcomers with the offer of an institutionalized socialization trajectory combined with academic training. This may entail a selection bias towards newcomers seeking a deliberate integration process on the job. Future research would obviously profit from bigger and more comparative samples, expanding the scope of the investigation beyond the cultural context of Germany or the setting of institutionalized socialization.

In terms of methodology, the research design presented here was to increase our understanding of how newcomers gain access to social(izing) capital through ties they are only just building up. Standardized methods of network data collection tell us about the kinds of ties focal actors have formed; yet, they usually stop short of an equally structured audit of the resources derived from these ties. Reconstructing tie mobilization, meanwhile, requires a qualitative form of inquiry, to elicit narratives from egos about how they realize the social capital potential of their networks. Such narratives offer researchers access to individual understandings of the meaning of relationships and the variance of what is perceived to facilitate or hinder their development.

Both structured data and interview narratives offer an informative perspective on personal networks. However, since they represent different forms of data derived from different forms of inquiry, they are not easily combined in an integrated approach for their analysis and interpretation (Schoonenboom \& Johnson, 2017). QSA offers a methodological framework in which the respective strengths of quantified, visualized, and qualitative network data can each be retained and triangulated (Herz et al., 2015; Wald, 2014). This paper has demonstrated how QSA can be applied in a small-N study and extends its applicability with regard to two novel adaptations. First, QSA is here extended to an investigation of personal networks centered around the social capital derived from them, rather than focused on their structural characteristics. Second, the paper shows how QSA can be applied when a network visualization was not created collaboratively during the interview. It illustrates how the approach can also enable triangulation in studies collecting network data through standardized methods, using established name generator and name interpreter techniques, and then visualizing these data as the first step of theory-guided processing.

With regard to the analysis of (ego-)networks, scholars have repeatedly stressed that it is helpful not to unreflectively adopt, but to adapt methods in a research design, to leverage the informative potential of different approaches (Cunningham, Harrigan, Wu, \& O'Callaghan, 2013; McCarty, Lubbers, Vacca, \& Molina, 2019). However, adaptation entails its own challenges. Whereas QSA was developed to analyze network maps as static representations of a network, it is here applied to reconstruct processes that lead to its shape as a snapshot in time. The research question and conceptual model underlying this study focus on the mobilization and development of ties; yet, they must rely on retrospective and self-reported data from a focal actor to investigate them.

Its limitations notwithstanding, this study increases our understanding of how newcomer socialization through the development of personal networks and intra-organizational social 
capital is initiated. It identifies specific moderators to further explore in future research and on which to focus our efforts to "help organizations socialize newcomers and to help newcomers self-socialize more effectively" (Fang et al., 2011, p. 130).

Acknowledgments. Earlier versions of this paper have profited substantially from the helpful feedback provided by Paul H.J. Hendriks, the QSA community, and ]rnnr[-group as well as Bernice A. Pescosolido and two anonymous Network Science reviewers.

Funding. DAAD—Deutscher Akademischer Austauschdienst (German Academic Exchange Service).

Conflict of interest. Sabine Bakker has nothing to disclose.

\section{References}

Adler, P. S., \& Kwon, S.-W. (2002). Social capital: Prospects for a new concept. Academy of Management Review, 27(1), 17-40. https://doi.org/10.5465/amr.2002.5922314

Allen, D. (2006). Do organizational socialization tactics influence newcomer embeddedness and turnover? Journal of Management, 32(2), 237-256. https://doi.org/10.1177/0149206305280103

Allen, D., \& Shanock, L. R. (2013). Perceived organizational support and embeddedness as key mechanisms connecting socialization tactics to commitment and turnover among new employees. Journal of Organizational Behavior, 34, 350-369. https://doi.org/10.1002/job.1805

Ash, B. E., Saks, A. M., \& Lee, R. T. (1998). Socialization and newcomer adjustment: The role of organizational context. Human Relations, 51(7), 879-926. https://doi.org/10.1023/A:1016999527596

Batistič, S. (2014). Organizational socialization tactics, individual differences, and the relationship building process in early socialization: A personal network change perspective. Reading: University of Reading. https://ethos.bl.uk/OrderDetails.do?uin=uk.bl.ethos. 658008

Batistič, S., \& Tymon, A. (2017). Networking behaviour, graduate employability: A social capital perspective. Education + Training, 59(4), 374-388. https://doi.org/10.1108/ET-06-2016-0100

Bauer, T. N., Bodner, T., Erdogan, B., Truxillo, D. M., \& Tucker, J. S. (2007). Newcomer adjustment during organizational socialization: A meta-analytic review of antecedents, outcomes, and methods. Journal of Applied Psychology, 92(3), 707721. https://doi.org/10.1037/0021-9010.92.3.707

Bauer, T. N., \& Erdogan, B. (2014). Delineating and reviewing the role of newcomer capital in organizational socialization. Annual Review of Organizational Psychology and Organizational Behavior, 1, $439-457$. https://doi.org/10.1146/annurev-orgpsych-031413-091251

Block, P., \& Grund, T. (2014). Multidimensional homophily in friendship networks. Network Science, 2(2), $189-212$. https://doi.org/10.1017/nws.2014.17

Borgatti, S. P., \& Foster, P. C. (2003). The network paradigm in organizational research: A review and typology. Journal of Management, 29(6), 991-1013. https://doi.org/10.1016/S0149-20630300087-4

Bourdieu, P. (1983). Ökonomisches Kapital, kulturelles Kapital, soziales Kapital. In R. Kreckel (Ed.), Soziale Ungleichheiten. Soziale Welt - Sonderband 2 (pp. 183-198). Göttingen: Schwartz.

Bozionelos, N. (2008). Intra-organizational network resources - How they relate to career success and organizational commitment. Personnel Review, 37(3), 249-263. https://doi.org/10.1108/00483480810862251

Burt, R. S. (1997). The contingent value of social capital. Administrative Science Quarterly, 42, $339-365$. https://doi.org/10.2307/2393923

Burt, R. S. (2001). Bandwidth and echo: Trust, information, and gossip in social networks. In A. Casella \& J. E. Rauch (Eds.), Networks and markets: Contribution from economics and sociology (pp. 1-37). New York: Russell Sage Foundation.

Cable, D. M., Gino, F., \& Staats, B. R. (2013). Breaking them in or eliciting their best? Reframing socialization around newcomers' authentic self-expression. Administrative Science Quarterly, 58(1), 1-36. https://doi.org/10.1177/0001839213477098

Cunningham, P., Harrigan, M., Wu, G., \& O’Callaghan, D. (2013). Characterizing ego-networks using motifs. Network Science, 1(2), 170-190. https://doi.org/10.1017/nws.2013.12

Dahlander, L., \& McFarland, D. A. (2013). Ties that last: Tie formation and persistence in research collaborations over time. Administrative Science Quarterly, 58(1), 69-110. https://doi.org/10.1177/0001839212474272

Devadason, R. (2011). Metaphor, social capital and sociological imaginaries. Sociological Review, 59(3), 633-654. https://doi.org/10.1111/j.1467-954X.2011.02027.x

Fang, R., Duffy, M. K., \& Shaw, J. D. (2011). The organizational socialization process: Review and development of a social capital model. Journal of Management, 37(1), 127-152. https://doi.org/10.1177/0149206310384630

Fang, R., Landis, B., Zhang, Z., Anderson, M. H., Shaw, J. D., \& Kilduff, M. (2015). Integrating personality and social networks: A meta-analysis of personality, network position, and work outcomes in organizations. Organization Science, 26(4), $1243-$ 1260. https://doi.org/10.1287/orsc.2015.0972 
Flap, H., \& Völker, B. (2001). Goal specific social capital and job satisfaction: Effects of different types of networks on instrumental and social aspects of work. Social Networks, 23(4), 297-320. https://doi.org/10.1016/S0378-8733(01)00044-2

Francesconi, M., \& Parey, M. (2018). Early gender gaps among university graduates. European Economic Review, $109,63-82$. https://doi.org/10.1016/j.euroecorev.2018.02.004

Gargiulo, M., \& Benassi, M. (2000). Trapped in your own net? Network cohesion, structural holes, and the adaptation of social capital. Organization Science, 11(2), 183-196. https://doi.org/10.1287/orsc.11.2.183.12514

Gioia, D. A., Corley, K. G., \& Hamilton, A. L. (2013). Seeking qualitative rigor in inductive research: Notes on the Gioia methodology. Organizational Research Methods, 16(1), 15-31. https://doi.org/10.1177/1094428112452151

Granovetter, M. S. (1983). The strength of weak ties: A network theory revisited. Sociological Theory, 1, $201-233$. https://doi.org/10.2307/202051

Gulati, R., Lavie, D., \& Madhavan, R. (2011). How do networks matter? The performance effects of interorganizational networks. Research in Organizational Behavior, 31, 207-224. https://doi.org/10.1016/j.riob.2011.09.005

Hansen, M. T. (1999). The search-transfer problem: The role of weak ties in sharing knowledge across organization subunits. Administrative Science Quarterly, 44, 82-111. https://doi.org/10.2307/2667032

Harris, T. B., Li, N., Boswell, W. R., Zhang, X. A., \& Xie, Z. (2014). Getting what's new from newcomers: Empowering leadership, creativity, and adjustment in the socialization context. Personnel Psychology, 67, 567-604. https://doi.org/10.1111/peps.12053

Hatala, J. P. (2006). Social network analysis in human resource development: A new methodology. Human Resource Development Review, 5(1), 45-71. https://doi.org/10.1177/1534484305284318

Herz, A., Peters, L., \& Truschkat, I. (2015). How to do Qualitative Structural Analysis: The qualitative interpretation of network maps and narrative interviews. Forum Qualitative Sozialforschung/Forum: Qualitative Social Research, 16(1), 1-24. https://doi.org/10.17169/fqs-16.1.2092

Higgins, M. C., \& Kram, K. E. (2001). Reconceptualizing mentoring at work: A developmental network perspective. The Academy of Management Review, 26(2), 264-288. https://doi.org/10.2307/259122

Holtom, B. C., Mitchell, T. R., \& Lee, T. W. (2006). Increasing human and social capital by applying job embeddedness theory. Organizational Dynamics, 35(4), 316-331. https://doi.org/10.1016/j.orgdyn.2006.08.007

Ibarra, H. (1993). Personal networks of women and minorities in management: A conceptual framework. Academy of Management Review, 18(1), 56-87. https://doi.org/10.2307/258823

Iseke, A. (2007). Sozialkapitalbildung in Organisationen. München: Hampp.

Jokisaari, M., \& Nurmi, J. E. (2012). Getting the right connections? The consequences and antecedents of social networks in newcomer socialization. In C. R. Wanberg (Ed.), The Oxford handbook of organizational socialization (pp. 78-96). Oxford: Oxford University Press.

Korte, R., \& Lin, S. (2013). Getting on board: Organizational socialization and the contribution of social capital. Human Relations, 66(3), 407-428. https://doi.org/10.1177/0018726712461927

Lane, J. L., \& Sweeny, S. P. (2019). Understanding agency and organization in early career teachers' professional tie formation. Journal of Educational Change, 20(1), 79-104. https://doi.org/10.1007/s10833-018-9329-0

Lee, R. (2009). Social capital and business and management: Setting a research agenda. International Journal of Management Reviews, 11(3), 247-273. https://doi.org/10.1111/j.1468-2370.2008.00244.x

Levin, D. Z., Walter, J., Appleyard, M. M., \& Cross, R. (2016). Relational enhancement: How the relational dimension of social capital unlocks the value of network-bridging ties. Group \& Organization Management, 41(4), 415-457. https://doi.org/10.1177/1059601115574429

Lin, N. (1999). Building a network theory of social capital. Connections, 22(1), 28-51.

Maak, T. (2007). Responsible leadership, stakeholder engagement, and the emergence of social capital. Journal of Business Ethics, 74(4), 329-343. https://doi.org/10.1007/s10551-007-9510-5

McCarty, C., Lubbers, M. J., Vacca, R., \& Molina, J. L. (2019). Conducting personal network analysis - A practical guide. New York: The Guildford Press.

Mitchell, T. R., Holtom, B. C., Lee, T. W., Sablynski, C. J., \& Erez, M. (2001). Why people stay: Using job embeddedness to predict voluntary turnover. Academy of Management Journal, 44(6), 1102-1121. https://doi.org/10.2307/3069391

Mollenhorst, G., Volker, B., \& Flap, H. (2014). Changes in personal relationships: How social contexts affect the emergence and discontinuation of relationships. Social Networks, 37(1), 65-80. https://doi.org/10.1016/j.socnet.2013.12.003

Morrison, E. W. (1993). Longitudinal study of the effects of information seeking on newcomer socialization. Journal of Applied Psychology, 78(2), 173-183. https://doi.org/10.1037/0021-9010.78.2.173

Morrison, E. W. (2002). Newcomers' relationships: The role of social network ties during socialization. The Academy of Management Journal, 45(6), 1149-1160. https://doi.org/10.2307/3069430

Nahapiet, J., \& Ghoshal, S. (1998). Social capital, intellectual capital, and the organizational advantage. The Academy of Management Review, 23(2), 242-266. https://doi.org/10.2307/259373

Ostroff, C., \& Kozlowski, S. W. J. (1992). Organizational socialization as a learning process: The role of information acquisition. Personnel Psychology, 45, 849-874. https://doi.org/10.1111/j.1744-6570.1992.tb00971.x 
Perry-Smith, J. E., \& Shalley, C. E. (2015). The social side of creativity: A static and dynamic social network perspective. The Academy of Management Review, 28(1), 89-106. https://doi.org/10.2307/30040691

Portes, A. (1998). Social capital: Its origins and applications in modern sociology. Annual Review of Sociology, 24(1), 1-24. https://doi.org/10.1146/annurev.soc.24.1.1

Randel, A. E., \& Ranft, A. L. (2007). Motivations to maintain social ties with coworkers: The moderating role of turnover intentions on information exchange. Group \& Organization Management, 32(2), $208-232$. https://doi.org/10.1177/1059601106286778

Riemer, K. (2005). Sozialkapital und Kooperation. Zur Rolle von Sozialkapital im Management zwischenbetrieblicher Kooperationsbeziehungen. Tübingen: Mohr Siebeck.

Ripperger, T. (2003). Ökonomik des Vertrauens. Tübingen: Mohr Siebeck.

Schönhuth, M., Kronenwett, M., Gamper, M., \& Stark, M. (2014). VennMaker 2.0.0. Retrieved from http://www.vennmaker.com

Schoonenboom, J., \& Johnson, R. B. (2017). How to construct a mixed methods research design. KZfSS Kölner Zeitschrift Für Soziologie Und Sozialpsychologie, 69, 107-131. https://doi.org/10.1007/s11577-017-0454-1

Slaughter, J. E., \& Zickar, M. J. (2006). A new look at the role of insiders in the newcomer socialization process. Group and Organization Management, 31(2), 264-290. https://doi.org/10.1177/1059601104273065

Small, M. L., Deeds Pamphile, V., \& McMahan, P. (2015). How stable is the core discussion network? Social Networks, 40, 90-102. https://doi.org/10.1016/j.socnet.2014.09.001

Small, M. L., \& Sukhu, C. (2016). Because they were there: Access, deliberation, and the mobilization of networks for support. Social Networks, 47, 73-84. https://doi.org/10.1016/j.socnet.2016.05.002

Spillane, J. P., Kim, C. M., \& Frank, K. A. (2012). Instructional advice and information providing and receiving behavior in elementary schools: Exploring tie formation as a building block in social capital development. American Educational Research Journal, 49(6), 1112-1145. https://doi.org/10.3102/0002831212459339

van der Werff, L., \& Buckley, F. (2017). Getting to know you: A longitudinal examination of trust cues and trust development during socialization. Journal of Management, 43(3), 742-770. https://doi.org/10.1177/0149206314543475

Wald, A. (2014). Triangulation and validity of network data. In S. Domínguez \& B. Hollstein (Eds.), Mixed methods in social networks research. Design and applications (pp. 65-89). New York: Cambridge University Press.

Zhang, M., Fried, D. D., \& Griffeth, R. W. (2012). A review of job embeddedness: Conceptual, measurement issues, and directions for future research. Human Resource Management Review, 22, 220-231. https://doi.org/10.1016/j.hrmr.2012.02.004

Cite this article: Bakker S. (2020). Mobilizing nascent ties: A qualitative structural analysis of social(izing) capital in newcomer networks. Network Science 8, 381-398. https://doi.org/10.1017/nws.2020.25 